ARTICLE

https://doi.org/10.1038/s41467-019-14168-0

\title{
Strategy to control magnetic coercivity by elucidating crystallization pathway-dependent microstructural evolution of magnetite mesocrystals
}

\author{
Bum Chul Park ${ }^{1,2,5}$, Jiung $\mathrm{Cho}^{3,5}$, Myeong Soo Kim4, Min Jun Ko, Lijun Pan ${ }^{1}$, Jin Yeong $\mathrm{Na}^{3}$ \& \\ Young Keun Kim (1) 1,4*
}

\begin{abstract}
Mesocrystals are assemblies of smaller crystallites and have attracted attention because of their nonclassical crystallization pathway and emerging collective functionalities. Understanding the mesocrystal crystallization mechanism in chemical routes is essential for precise control of size and microstructure, which influence the function of mesocrystals. However, microstructure evolution from the nucleus stage through various crystallization pathways remains unclear. We propose a unified model on the basis of the observation of two crystallization pathways, with different ferric (oxyhydr)oxide polymorphs appearing as intermediates, producing microstructures of magnetite mesocrystal via different mechanisms. An understanding of the crystallization mechanism enables independent chemical control of the mesocrystal diameter and crystallite size, as manifested by a series of magnetic coercivity measurements. We successfully implement an experimental model system that exhibits a universal crystallite size effect on the magnetic coercivity of mesocrystals. These findings provide a general approach to controlling the microstructure through crystallization pathway selection, thus providing a strategy for controlling magnetic coercivity in magnetite systems.
\end{abstract}

\footnotetext{
${ }^{1}$ Department of Materials Science and Engineering, Korea University, Seoul 02481, Korea. ${ }^{2}$ Research Institute of Engineering and Technology, Korea University, Seoul 02481, Korea. ${ }^{3}$ Western Seoul Center, Korea Basic Science Institute, Seoul 03759, Korea. ${ }^{4}$ Department of Biomicrosystem Technology, Korea University, Seoul 02481, Korea. ${ }^{5}$ These authors contributed equally: Bum Chul Park, Jiung Cho. *email: ykim97@korea.ac.kr
} 
$\mathrm{M}$ agnetic coercivity behavior is essential for demonstrating magnetism in fine particles and is also a crucial performance indicator for a wide range of electrical and biomedical applications ${ }^{1-5}$. Of many magnetic materials, magnetite $\left(\mathrm{Fe}_{3} \mathrm{O}_{4}\right)$, which is biocompatible and exhibits superparamagnetic-ferrimagnetic transition depending on its size, has been extensively studied as a diagnostic and therapeutic reagent, leading to advances in the biomedical field ${ }^{1,6}$. To date, shape, size, and composition are used to control magnetic coercivity for applications such as magnetic particle imaging (MPI), which require nonlinear magnetism or magnetic hyperthermia requiring hysteresis loss. However, remarkable advances currently appear unlikely ${ }^{5}$. The microstructure provides a breakthrough in the control of coercivity because crystallite size and inter-crystallite magnetic interaction are closely related to coercivity $^{1-3}$. To verify this at the nanoscale, the magnetic mesocrystal (an assembly of smaller crystallites) is a promising model system for exhibiting collective magnetic coercivity behavior influenced by individual crystallites ${ }^{7-9}$. Magnetic mesocrystals have been reported to exhibit magnetic properties dissimilar from those of single-crystalline particles, depending on the structural arrangement and the magnetic coupling between crystallites. However, we still do not understand the correlation between the microstructure of the mesocrystal and its magnetic properties due to the complexity of the phenomenon. Controlling the crystallite size of mesocrystals at the nanoscale would experimentally reveal this correlation, but chemically controlling the microstructure of mesocrystals synthesized in a bottom-up process still remains a challenge.

The correlation between the microstructure of the $\mathrm{Fe}_{3} \mathrm{O}_{4}$ mesocrystal and its crystallization pathway is an essential underpinning of this study. Understanding the crystallization mechanism in chemical routes is crucial for precise control of the microstructure of $\mathrm{Fe}_{3} \mathrm{O}_{4}$ mesocrystals, which affects magnetic functions. In general, the crystallization mechanism of materials is described by the classical nucleation and growth theory, through which the crystals are spontaneously nucleated in solution and are grown after reaching critical size. For several systems, crystalline phases are not formed directly from solution but by stepwise phase transformations preceded by metastable intermediates ${ }^{10-12}$. Formation of metastable intermediates advances with solubility, and are governed by the Ostwald step rule that the phases with a lower kinetic energy barrier are formed prior to the one with a higher barrier ${ }^{13}$. Recently, several mechanisms besides the classical nucleation and growth model have been observed during the transformation steps of intermediate or crystalline phases $^{14,15}$. In particular, depending on the particle attachment model, mesocrystals comprising assemblies of smaller crystallites frequently exhibit a nonclassical pathway in which crystallization proceeds via attachment of nanometric building blocks (including prenucleation clusters or nanoparticles) and not atom accretion $^{16,17}$.

In these complex processes, the transient metastable intermediate state acts as a precursor to the post-nucleation stage in which the crystalline phase is formed. This intermediate state affects the type and structure of the final crystalline phase, as proposed primarily in calcium carbonate $\left(\mathrm{CaCO}_{3}\right)$, calcium phosphate $\left(\mathrm{Ca}_{3}\left(\mathrm{PO}_{4}\right)_{2}\right)$, and calcium sulfate $\left(\mathrm{CaSO}_{4}\right)$ systems ${ }^{18-20}$. The $\mathrm{Fe}_{3} \mathrm{O}_{4}$ phase is also commonly formed stepwise through a series of intermediates down to the lowest-energy rather than being formed directly from ionic precursors ${ }^{21-23}$. For $\mathrm{Fe}_{3} \mathrm{O}_{4}$, various types of ferric (oxyhydr)oxide polymorphs [e.g., $\alpha$ $\mathrm{FeO}(\mathrm{OH}), \beta-\mathrm{FeO}(\mathrm{OH})$, and $\gamma-\mathrm{FeO}(\mathrm{OH})]$ and ferrihydrite have been observed as intermediates. Because ferric (oxyhydr)oxide polymorphs represent similar solubilities, the types of intermediates appearing before the $\mathrm{Fe}_{3} \mathrm{O}_{4}$ phase can be significantly varied based on experimental conditions such as $\mathrm{pH}$, additive content, and $\mathrm{Fe}^{3+}$ and $\mathrm{Fe}^{2+}$ cation concentrations ${ }^{23-25}$. Furthermore, nonclassical crystallization mechanisms, which occur in the formation of ferric (oxyhydr)oxide intermediate or $\mathrm{Fe}_{3} \mathrm{O}_{4}$, can also affect the type of intermediate ${ }^{26-30}$. Baumgartner et al. observed the crystallization process via particle attachment in $\mathrm{Fe}_{3} \mathrm{O}_{4}$ formation and proposed that the energetic stability of primary crystallites can influence the presence of ferrihydrite intermediates ${ }^{28}$. These prior observations provide useful experimental and theoretically indications regarding the role of crystallization pathways. However, we still cannot fully explain the pathways via a universal mechanism, and the evolution of the microstructure during the reaction remains unclear.

In this study, we provide two crystallization pathways of $\mathrm{Fe}_{3} \mathrm{O}_{4}$ mesocrystals in which different ferric (oxyhydr)oxide polymorphs appear separately as intermediates on each pathway. We uncover that the microstructure of $\mathrm{Fe}_{3} \mathrm{O}_{4}$ mesocrystal is affected by which pathway governs the overall reaction and can be chemically controlled by polymorph selection of iron (oxyhydr)oxide. Based on this understanding, diameter and crystallite size of $\mathrm{Fe}_{3} \mathrm{O}_{4}$ mesocrystals are controlled independently. Finally, we report the successful experimental implementation of the crystallite size effect of $\mathrm{Fe}_{3} \mathrm{O}_{4}$ mesocrystal on the magnetic coercivity curves as a function of the diameter. Because $\mathrm{Fe}_{3} \mathrm{O}_{4}$ mesocrystals represent crystallographically ordered aggregate of spheres, we can discuss the collective coercivity behavior, which is difficult to observe in singular particle.

\section{Results}

Microstructure control via crystallization pathway selection. We hypothesized that if the $\mathrm{Fe}_{3} \mathrm{O}_{4}$ phase was formed from different ferric (oxyhydr)oxide polymorphs as intermediates, there would be differences in the microstructure of the $\mathrm{Fe}_{3} \mathrm{O}_{4}$ mesocrystal because of the different crystallization mechanisms. If possible, we could chemically control the microstructure by selecting an intermediate among the polymorphs, and eventually, change the crystallite size of the $\mathrm{Fe}_{3} \mathrm{O}_{4}$ mesocrystal. To verify our hypothesis, we observe the crystallization pathways of $\mathrm{Fe}_{3} \mathrm{O}_{4}$ mesocrystals consisting of different crystallite sizes synthesized using the modified polyol method. We identified two crystallization pathways, shown in the schematic illustration (Fig. 1).

lepidocrocite $(\gamma-\mathrm{FeOOH}) \rightarrow$ magnetite $\left(\mathrm{Fe}_{3} \mathrm{O}_{4}\right)$ (Pathway 1)

lepidocrocite $(\gamma-\mathrm{FeOOH}) \rightarrow$ goethite $(\alpha-\mathrm{FeOOH}) \rightarrow$ magnetite $\left(\mathrm{Fe}_{3} \mathrm{O}_{4}\right)$ (Pathway 2).

In pathway $1, \mathrm{Fe}_{3} \mathrm{O}_{4}$ primary crystallites with a size of 3-4 nm are produced in the lepidocrocite matrices, and the $\mathrm{Fe}_{3} \mathrm{O}_{4}$ mesocrystals grow such that the crystals adhere to each other in the same crystallographic direction (nonclassical pathway). In pathway $2, \mathrm{Fe}_{3} \mathrm{O}_{4}$ does not form directly in the lepidocrocite but apparently forms via stepwise transformation from lepidocrocite and goethite, conforming with the Ostwald step rule (classical pathway). Broadly, the entire reaction proceeds concurrently through these classical and nonclassical pathways. However, each pathway produces $\mathrm{Fe}_{3} \mathrm{O}_{4}$ mesocrystal at different stages. In pathway 1 , the $\mathrm{Fe}_{3} \mathrm{O}_{4}$ mesocrystal forms at an early stage in the reaction, while in pathway 2 , it is nucleated at a later stage in the reaction. Further, the microstructure is affected by the pathway governing the entire reaction and can be chemically controlled. We confirmed that the size of the crystallites formed in pathway 1 is smaller than that of those formed in pathway 2 .

Crystallization processes of sample 1 and sample 2. We compared the formation process and microstructural evolution of $\mathrm{Fe}_{3} \mathrm{O}_{4}$ mesocrystals having the same $\sim 60 \mathrm{~nm}$ diameter $(D)$ 


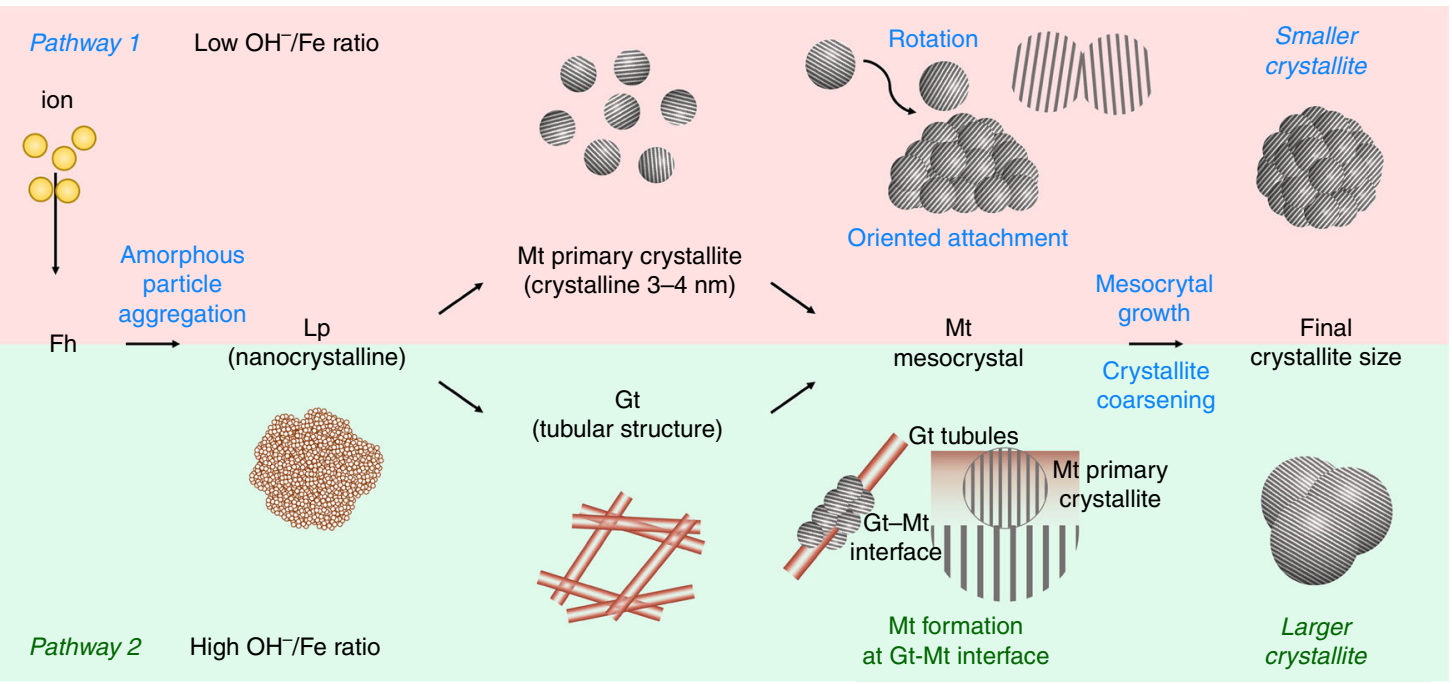

Fig. 1 Schematic illustration of the proposed crystallization model of the $\mathbf{F e}_{\mathbf{3}} \mathbf{O}_{\mathbf{4}}$ mesocrystal. The two crystallization pathways identified in this study: Pathway 1 (Fh-Lp-Mt: the growth mechanism of $\mathrm{Fe}_{3} \mathrm{O}_{4}$ is oriented attachment), and Pathway 2 (Fh-Lp-Gt-Mt: the growth mechanism of $\mathrm{Fe}_{3} \mathrm{O}_{4}$ is interfacecontrolled growth). Fh: $5 \mathrm{Fe}_{2} \mathrm{O}_{3} \cdot 9 \mathrm{H}_{2} \mathrm{O}$, $\mathrm{Lp}: \gamma-\mathrm{FeO}(\mathrm{OH}), \mathrm{Gt}: \alpha-\mathrm{FeO}(\mathrm{OH}), \mathrm{Mt}^{\mathrm{F}} \mathrm{Fe}_{3} \mathrm{O}_{4}$.

but different crystallite sizes $(C)$ of 23 and $43 \mathrm{~nm}$ (Sample 1 (S1): $D=62 \pm 3 \mathrm{~nm}, C=23 \pm 3 \mathrm{~nm}$; Sample 2 (S2): $D=61 \pm 4 \mathrm{~nm}$, $C=43 \pm 3 \mathrm{~nm}$ ) synthesized using $\mathrm{Fe}: \mathrm{NaOAC}: \mathrm{H}_{2} \mathrm{O}$ ratios of 2:15:150 and 1:3:200, respectively (Supplementary Figs. 1, 2). Uniform $60 \mathrm{~nm} \mathrm{Fe} \mathrm{O}_{4}$ mesocrystals are synthesized in both cases.

Figure 2 presents the formation process of $\mathrm{S} 1$ and $\mathrm{S} 2$ at various reflux times. The $\mathrm{Fe}_{3} \mathrm{O}_{4}$ mesocrystals grow much more rapidly in $\mathrm{S} 1$ than in S2 (Supplementary Figs. 3, 4). $\mathrm{Fe}_{3} \mathrm{O}_{4}$ mesocrystals of S1 and $\mathrm{S} 2$ are synthesized in different reaction stages from different intermediates. Transmission electron microscopy (TEM) results reveal that the cause of this difference in the initiation time of mesocrystal formation is due to the crystallization pathway rather than the reaction rate (Fig. 2a, b).

In $\mathrm{S} 1$, the $\mathrm{Fe}_{3} \mathrm{O}_{4}$ mesocrystal grows rapidly in the nanocrystalline intermediate (lepidocrocite) before refluxing for $3 \mathrm{~h}$, after which it grows in the tubular intermediate (goethite). Conversely, in S2, most of the nanocrystalline intermediates are transformed into tubular intermediates rather than $\mathrm{Fe}_{3} \mathrm{O}_{4}$ mesocrystals in the first $3 \mathrm{~h}$ of refluxing, and $\mathrm{Fe}_{3} \mathrm{O}_{4}$ mesocrystals began to grow primarily from the tubular intermediate. Both $\mathrm{S} 1$ and $\mathrm{S} 2$ show a similar crystallization process after $3 \mathrm{~h}$ refluxing. $\mathrm{Fe}_{3} \mathrm{O}_{4}$ mesocrystals in S1 grow primarily from a nanocrystalline intermediate before refluxing for $3 \mathrm{~h}$ (pathway 1), while that of $\mathrm{S} 2$ grows from a tubular intermediate after refluxing for $3 \mathrm{~h}$ (pathway 2). This indicates that S1 and S2 were grown through different crystallization pathways: S1 through pathway 1 and S2 through pathway 2 .

This phenomenon is well reflected in Fig. $2 \mathrm{c}$ which presents the changes in the diameter of the $\mathrm{Fe}_{3} \mathrm{O}_{4}$ mesocrystal over time for $\mathrm{S} 1$ and S2. The growth kinetics of S1 shows two-step growth, while that of S2 shows one-step growth. The growth kinetics of each crystallization pathway is clearly distinguishable around $3 \mathrm{~h}$. In S1, the $\mathrm{Fe}_{3} \mathrm{O}_{4}$ mesocrystals grew to $53 \mathrm{~nm}$ via pathway 1 and then grew an additional $9 \mathrm{~nm}$ via pathway 2 . In $\mathrm{S} 2, \mathrm{Fe}_{3} \mathrm{O}_{4}$ mesocrystals did not form on pathway 1 but grew after $3 \mathrm{~h}$ via pathway 2 . The formation of $\mathrm{Fe}_{3} \mathrm{O}_{4}$ mesocrystal via pathway 2 begins at similar times in both $\mathrm{S} 1$ and S2, which is illustrated by the green region of Fig. 2c.

Based on the X-ray diffraction (XRD) patterns (Fig. 2d, e), we could define the phases of nanocrystalline and tubular intermediates. In XRD patterns of $\mathrm{S} 1$ (Fig. 2d), the $\mathrm{Fe}_{3} \mathrm{O}_{4}$ [International Center for Diffraction Data (ICDD) no. 01-086-1344] and ferric (oxyhydr)oxide phases coexisted after $1.5 \mathrm{~h}$ of refluxing. The broad diffraction peaks are assigned primarily to poorly crystalline lepidocrocite (ICDD no. 00-044-1415). With increasing reflux time, the peaks of the $\mathrm{Fe}_{3} \mathrm{O}_{4}$ phase become prominent and sharpened. For S2, we identify the tubular intermediate phase observed primarily in pathway 2 (Fig. 2e). At $3.5 \mathrm{~h}$, the peak from lepidocrocite decreases, and that from goethite (ICDD no. 00029-0713) appears, indicating that tubular ferric (oxyhydr)oxide intermediates could be assigned to goethite, a polymorph of lepidocrocite.

Crystallization-pathway-dependent microstructural evolution. An analysis of the microstructure along each crystallization pathway is presented in Fig. 3. As shown in Fig. 3a, in the early stage of the reaction in $\mathrm{S} 1, \mathrm{Fe}_{3} \mathrm{O}_{4}$ mesocrystals, comprising spherical primary crystallites in nanocrystalline lepidocrocite intermediates, appear after $1 \mathrm{~h}$ of refluxing. In region 1 , the fast Fourier transform (FFT) pattern of the $\mathrm{Fe}_{3} \mathrm{O}_{4}$ mesocrystal appears as a spot pattern, indicating that the primary crystallites have slightly tilted and almost identical orientations. The spots closest to the center are indexed as the (220) family of planes of $\mathrm{Fe}_{3} \mathrm{O}_{4}$. This is the characteristic phenomenon of mesocrystal formation in which the building units are crystallographically aligned ${ }^{31}$. Figure $3 \mathrm{~b}$ shows that the FFT pattern of the primary crystallite on the $\mathrm{Fe}_{3} \mathrm{O}_{4}$ mesocrystal surface has the same crystallographic orientation as the core. The $\mathrm{Fe}_{3} \mathrm{O}_{4}$ mesocrystal and primary crystallites are attached along the direction of the (220) planes. In region 2, spherical intermediates appear and exhibit an unclear FFT pattern attributed to short-range order (Fig. 3a). The SAED pattern of the intermediates also forms a wide ring pattern, indicating that the intermediate phase exhibits poor crystallinity (Supplementary Fig. 5). After $1.5 \mathrm{~h}$ of refluxing, the growth of $\mathrm{Fe}_{3} \mathrm{O}_{4}$ mesocrystals through oriented attachment of the primary crystallites becomes prominent (Fig. 3c). Comparing the samples that reacted for 1 and $1.5 \mathrm{~h}$, the number of primary crystallites around the mesocrystals increases more rapidly as the reaction time increases. The FFT results gradually change from a single to polycrystalline ring pattern indexed as $\mathrm{Fe}_{3} \mathrm{O}_{4}$ with increasing distance from the mesocrystal. This is because the primary crystallites are randomly oriented at the periphery of the mesocrystal, unlike those on the surface of the mesocrystal. Furthermore, we measured the number and size of primary crystallites in the TEM images and observed that the size of the primary 

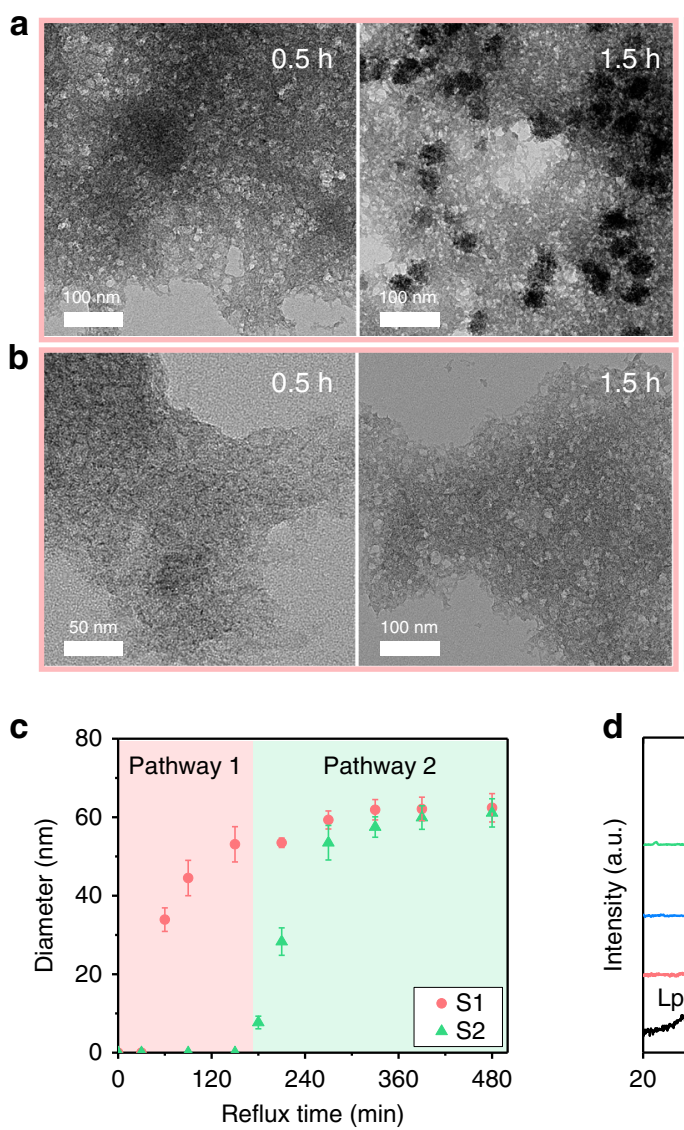
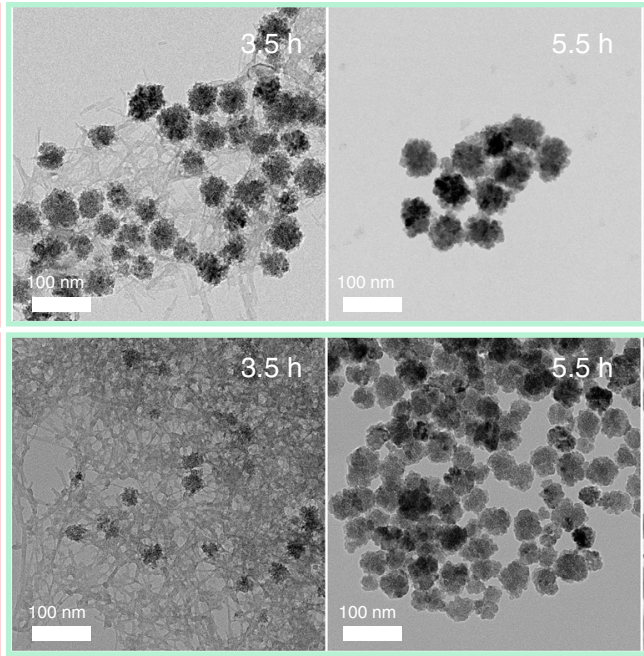
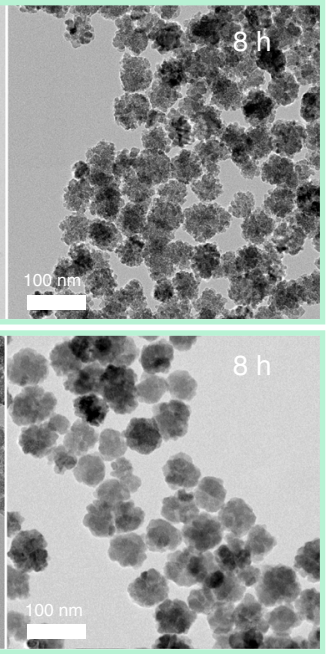

d

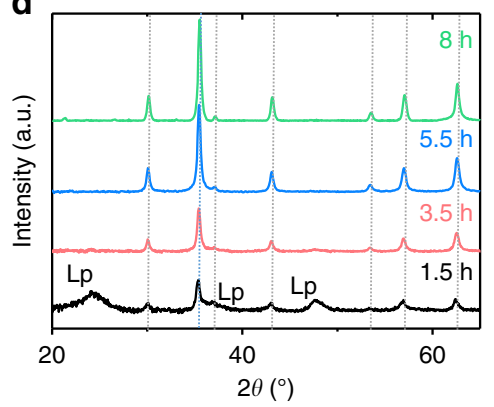

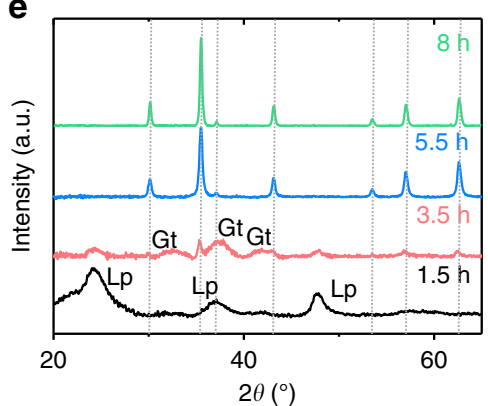

Fig. $\mathbf{2}$ Crystallization of $\mathbf{F e}_{\mathbf{3}} \mathbf{O}_{\mathbf{4}}$ mesocrystals in $\mathbf{S 1}$ and $\mathbf{S 2}$ during refluxing. $\mathbf{a}, \mathbf{b} \mathrm{TEM}$ images of a $\mathrm{S} 1$ and $\mathbf{b} \mathrm{S} 2$ after $0.5,1.5,3.5,5.5$, and $8 \mathrm{~h}$ of refluxing.

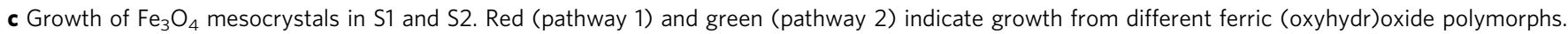
Diameters are mean values of the Gaussian function measured from $n>200$ mesocrystals in TEM images; error bars indicate standard deviations. d, e XRD patterns of $\mathbf{d}$ S1 and e S2. Lepidocrocite (Lp), goethite (Gt), and magnetite (Mt) are indexed using ICDD no. 00-044-1415, 00-029-0713, and 01-086-1344 (gray dotted line), respectively.

crystallites is fixed at $3.5 \pm 0.3 \mathrm{~nm}$, but their number increases 2.8 times as the $\mathrm{Fe}_{3} \mathrm{O}_{4}$ mesocrystal grows (Fig. $3 \mathrm{~d}$ ). This suggests that the growth mode can be attributed to the attachment of primary crystallites and not the accretion of ions or atoms.

We investigate crystallization pathway 2 of the $\mathrm{Fe}_{3} \mathrm{O}_{4}$ mesocrystal by analyzing the microstructure of $\mathrm{S} 2$ in which the mesocrystal crystallizes primarily from tubular goethite (Fig. 3e). We observed a consistent phenomenon in the later stage of the reaction in S1 (Supplementary Fig. 6). The structures of tubular goethite and the $\mathrm{Fe}_{3} \mathrm{O}_{4}$ mesocrystals are clearly distinguishable using high-resolution transmission electron microscopy (HRTEM) after $4.5 \mathrm{~h}$ (Fig. 3e). The FFT pattern of the mesocrystals is a single pattern, with the zone axis in the [011] direction. The $\mathrm{Fe}_{3} \mathrm{O}_{4}$ mesocrystals are grown at places where they have an interface with goethite, and the newly formed crystallites follow the crystallographic orientation of preexisting $\mathrm{Fe}_{3} \mathrm{O}_{4}$ mesocrystals. Phases other than goethite rarely appear in the FFT patterns away from the mesocrystals. The goethite intermediate exhibits a tubular structure with an external diameter of $2.5-4 \mathrm{~nm}$, an inner diameter of $1-1.5 \mathrm{~nm}$, and a wall thickness of $0.8-1.6 \mathrm{~nm}$ (Supplementary Fig. 7). Because it is difficult for this ultra-thin tubular structure to have a long-range order, the FFT pattern suggests poor crystallinity, with a ring pattern that is associated with the (021) plane. Ferric (oxyhydr) oxides exhibit characteristic Raman peaks depending on their polymorphs, and the Raman spectrum of S2 reacted for $4.5 \mathrm{~h}$ has the characteristic peaks of magnetite and goethite (Supplementary Fig. 7) at 680 and $384 \mathrm{~cm}^{-1}$, respectively ${ }^{32}$.
Adjacent primary crystallites constituting the $\mathrm{Fe}_{3} \mathrm{O}_{4}$ mesocrystals in both samples are coarsened and densely packed, with the appropriate orientation (Supplementary Fig. 6). The size of the crystallite is determined by the post-coarsening process due to variations in the reactant concentrations, with S1, dominated by pathway 1 , having smaller crystallites than that with $\mathrm{S} 2$, which is dominated by pathway 2 .

Growth kinetics of crystallization pathways. As discussed in the preceding sections, two coexisting pathways are competitively responsible for the crystallization process of $\mathrm{Fe}_{3} \mathrm{O}_{4}$ mesocrystals. They originate from different mechanisms and participate in different stages of the reaction to form $\mathrm{Fe}_{3} \mathrm{O}_{4}$ mesocrystals that exhibit distinct growth kinetics. Because the nucleation and growth of $\mathrm{Fe}_{3} \mathrm{O}_{4}$ mesocrystals can be explained through phase transformation under isothermal conditions, from ferric (oxyhydr)oxide intermediates to the $\mathrm{Fe}_{3} \mathrm{O}_{4}$ phase, we can gain more insight into the crystallization of $\mathrm{Fe}_{3} \mathrm{O}_{4}$ mesocrystals in $\mathrm{S} 1$ and $\mathrm{S} 2$ using the Johnson-Mehl-Avrami-Kolmogorov (JMAK) model (Fig. 4) ${ }^{33}$. This model has been extensively applied to phase transformation and polymorphic transformation of solid phase that occurs via nucleation and growth. It is expressed as $f=1-\exp \left[-(k t)^{n}\right]$, where $f$ is the volume fraction of the transformed volume, $t$ is reflux time, $k$ is a constant, and $n$ is the Avrami exponent. The Avrami exponent is written as $n=a+(b \times c)$, where $a$ is the time-dependent nucleation rate $(a>0), b$ is the dimensionality of the grown phase $(0<b<3)$, and $c$ is the growth rate $(c=0.5 \text { or } 1)^{33-35}$. 
a

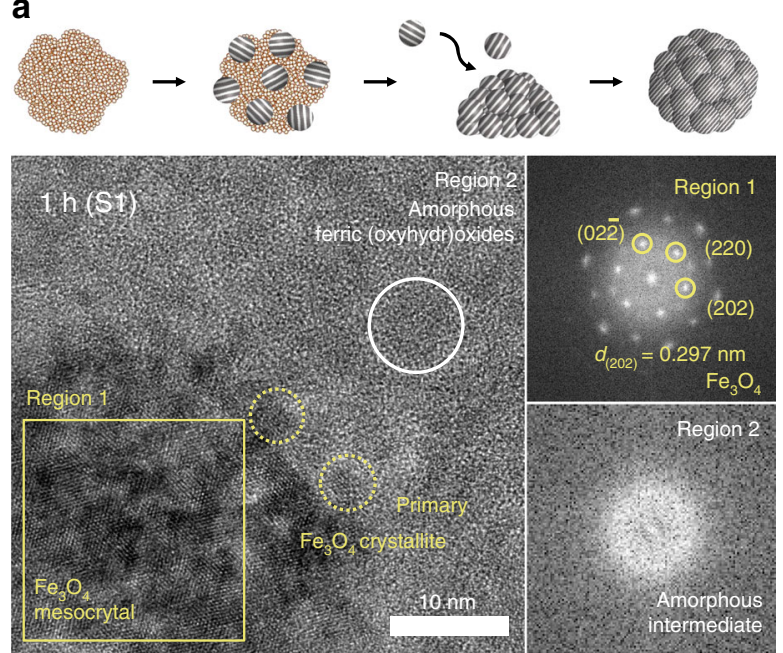

C
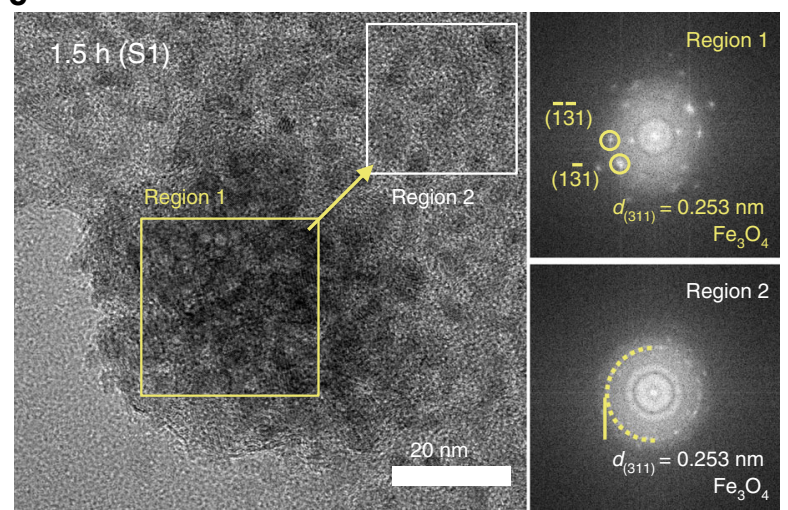

e
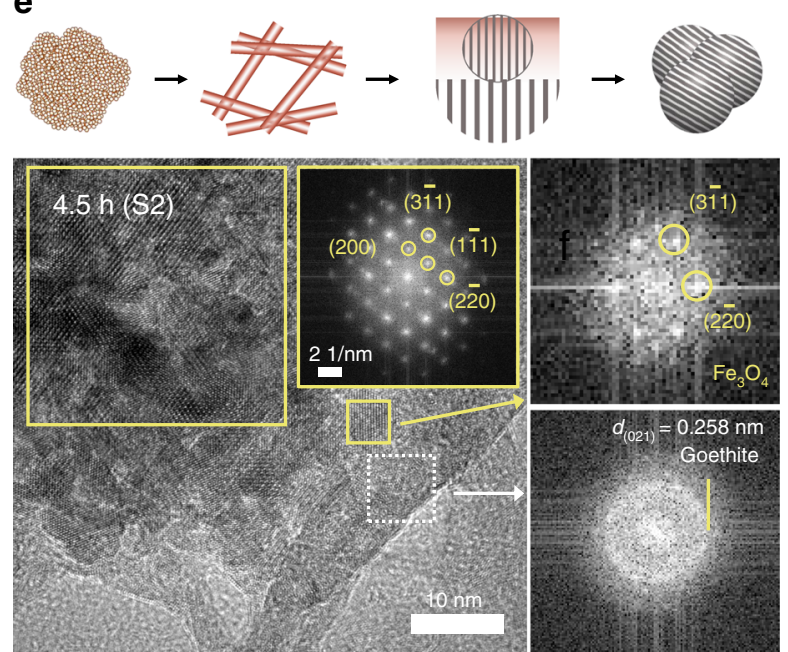

b

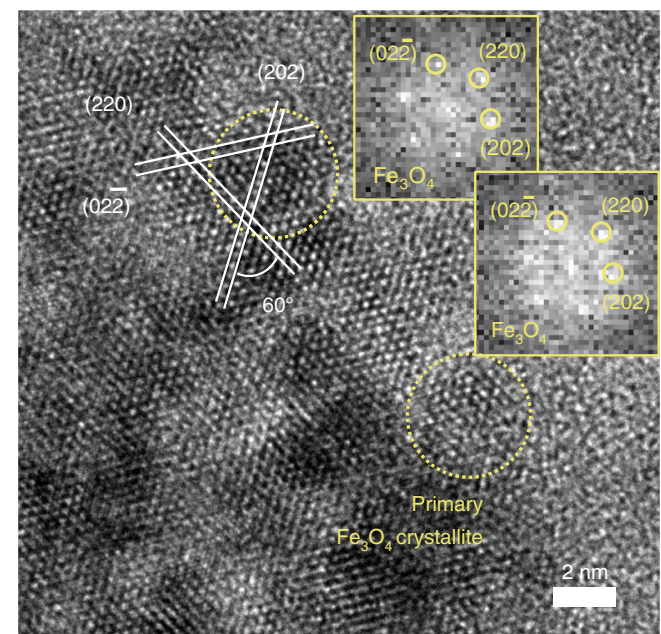

d

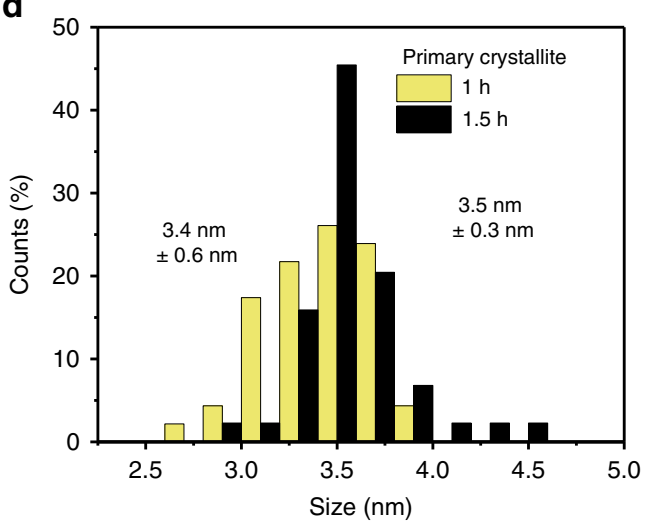

$\mathbf{f}$

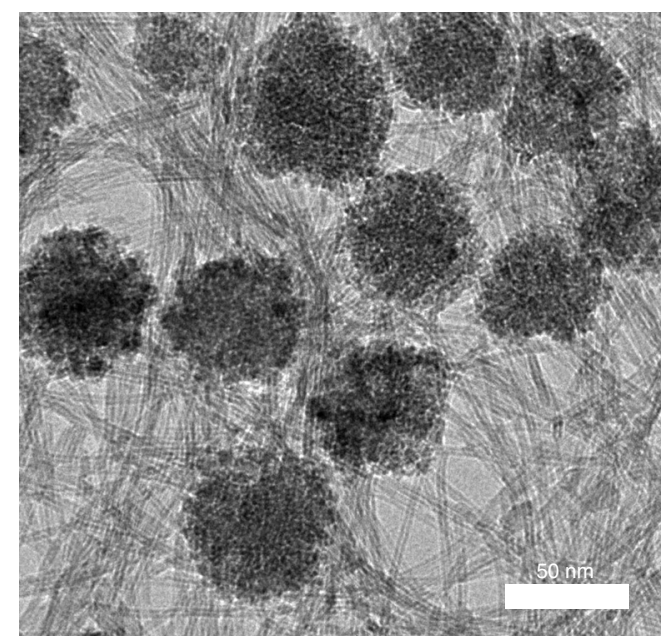

Fig. 3 Microstructural analysis of crystallization pathways. a TEM analysis of $\mathrm{Fe}_{3} \mathrm{O}_{4}$ mesocrystals of $\mathrm{S} 1$ after refluxing for $1 \mathrm{~h}$. b HRTEM image showing FFT images of primary crystallites attached to the surface of mesocrystals in S1 after refluxing for $1 \mathrm{~h}$. c TEM images and FFT patterns of S1 after refluxing for $1.5 \mathrm{~h}$. The Regions for FFT patterns are indicated in each bright field image of a-c. The phase and corresponding d-spacing of the FFT patterns are denoted in each panel. d Sizes of primary crystallites after 1 and $1.5 \mathrm{~h}$ of refluxing. A Gaussian distribution is obtained from the measured sizes of $n=50$ mesocrystals. e HRTEM image and FFT patterns of S2 after refluxing for $4.5 \mathrm{~h}$. The FFT pattern shows d-spacing of spots derived from the magnetite and goethite closest to the center. $\mathbf{f}$ Bright-field image of $\mathrm{S} 2$ after refluxing for $4.5 \mathrm{~h}$.

Figure $4 \mathrm{a}$ shows the timeline of the reaction and the JMAK model. We applied the model separately for each pathway because the kinetics of the transformation depends on the ferric (oxyhydr)oxide polymorph from which the $\mathrm{Fe}_{3} \mathrm{O}_{4}$ mesocrystals originate. Neither S1 nor S2 contains any phase other than $\mathrm{Fe}_{3} \mathrm{O}_{4}$ after the reaction is complete. Thus, we regard $f$ as the volume fraction grown at a particular time with respect to the final volume formed at the end of each pathway (Supplementary 
a
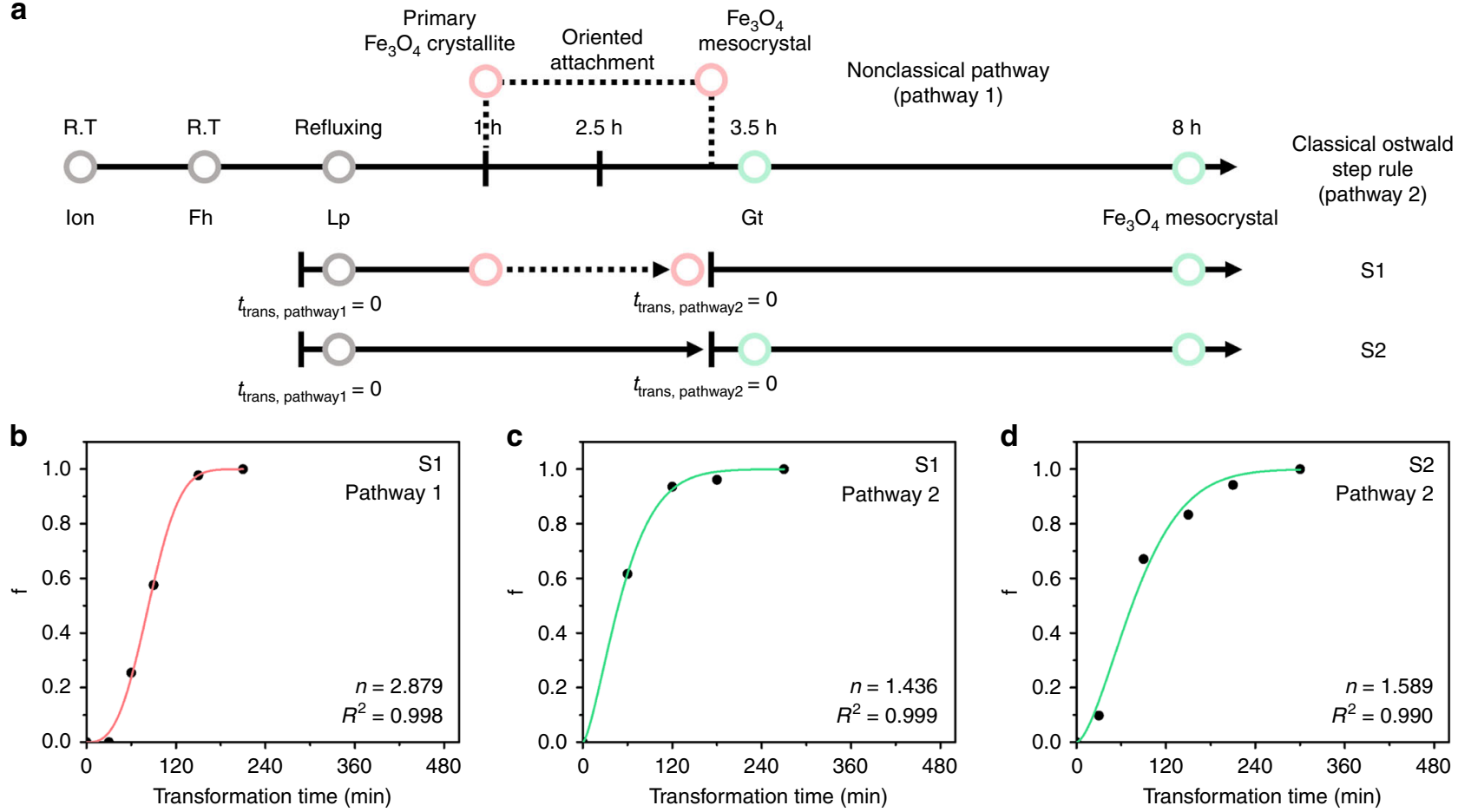

Fig. 4 JMAK Kinetics and schematic illustration of the proposed crystallization model of $\mathbf{F e}_{\mathbf{3}} \mathbf{O}_{\mathbf{4}}$. a Timeline of the entire reaction, and JMAK kinetics. Phases at each time are indicated. Solid and dotted lines represent crystallization pathways 1 and 2, respectively. b-d Fitting results of JMAK model of $\mathrm{Fe}_{3} \mathrm{O}_{4}$ mesocrystals grown via pathway 1 of $\mathrm{S} 1(\mathbf{b})$, pathway 2 of $\mathrm{S} 1(\mathbf{c})$, and pathway 2 of $\mathrm{S} 2(\mathbf{d})$. Transformation time $\left(t_{\text {trans }}\right)=0$ is defined as the starting point of each process. Red and green lines indicate the crystallization pathway 1 and 2, respectively.

Fig. 8). We confirmed that growth in each pathway follows the prediction of the JMAK model: the Avrami exponents of S1 (pathway 1), S1 (pathway 2), and S2 (pathway 2) are 2.89, 1.436, and 1.589 , respectively (Fig. $4 \mathrm{~b}-\mathrm{c}$ ). The $n$ value was derived differently based on the crystallization pathway, where the $n$ from lepidocrocite $\rightarrow \mathrm{Fe}_{3} \mathrm{O}_{4}$ was higher than that obtained from goethite $\rightarrow \mathrm{Fe}_{3} \mathrm{O}_{4}$. Furthermore, $n$ values derived from the transformation of goethite $\rightarrow \mathrm{Fe}_{3} \mathrm{O}_{4}$ in $\mathrm{S} 1$ (pathway 2) and $\mathrm{S} 2$ (pathway 2) are similar, which implies that the mechanism of each crystallization pathway is accurately reflected in the classical JMAK model. In S1 (pathway 1), there is spherical growth $(b=3)$ of $\mathrm{Fe}_{3} \mathrm{O}_{4}$ mesocrystals via oriented attachment of primary crystallites. It is hypothesized that a diffusion-controlled process $(c=0.5)$ determines the growth rate when primary crystallites approach each other. Here, $a$ is deduced to be 1.3-1.4, indicating the accelerated and autocatalytic nucleation rate ${ }^{35}$. This is in good agreement with the TEM results as the $\mathrm{Fe}_{3} \mathrm{O}_{4}$ primary crystallites formed from lepidocrocite gradually increase over time (Fig. $3 \mathrm{a}-\mathrm{c}$ ). $\mathrm{Fe}_{3} \mathrm{O}_{4}$ primary crystallites are increasingly nucleated in nanocrystalline lepidocrocite and attach to each other to grow mesocrystals. Furthermore, the $n$ values of pathway 2 for $\mathrm{S} 1$ and S2 are similar. Interface-controlled growth $(c=1)$ was confirmed by direct observation of $\mathrm{Fe}_{3} \mathrm{O}_{4}$ mesocrystal growth at the interface with goethite. Because the $\mathrm{Fe}_{3} \mathrm{O}_{4}$ mesocrystal are formed from one-dimensional tubular goethite intermediate and grow along the orientation of preexisting $\mathrm{Fe}_{3} \mathrm{O}_{4}$ mesocrystals, we can thus deduce one-dimensional growth $(b=1)$ and decreasing nucleation rate in pathway $2(a=0.4-0.6)$.

Chemical control of the crystallization pathways. We show that ferric (oxyhydr)oxide polymorphs play an essential role in determining the crystallization pathway of $\mathrm{Fe}_{3} \mathrm{O}_{4}$, which differentiates the microstructures of $\mathrm{Fe}_{3} \mathrm{O}_{4}$ mesocrystals derived via each crystallization mechanism. We propose that the crystallization pathways of $\mathrm{Fe}_{3} \mathrm{O}_{4}$ can be selected by varying the chemical content. Recent experimental and theoretical studies indicate that the solution chemistry affects the free-energy landscape that directly governs polymorph selection ${ }^{28,36,37}$. The freeenergy landscape is determined by the ratio of surface to bulk energy, which is a function of solution chemistry. Consequently, even minor variations in reactant type and concentration influence the phase is selected as intermediate among the ferric (oxyhydr)oxide polymorphs, which have different solubilities ${ }^{23,38,39}$. The graphs in Fig. 5a-c represent the effect of the chemical content including $\mathrm{FeCl}_{3} \cdot 6 \mathrm{H}_{2} \mathrm{O}, \mathrm{NaOAC}$, and $\mathrm{H}_{2} \mathrm{O}$ on the diameter and crystallite size of the $\mathrm{Fe}_{3} \mathrm{O}_{4}$ mesocrystals. The modified polyol method has been widely used for a decade, but we were able to observe changes in the diameter and crystallite size over a wide range of chemical content and developed a comprehensive understanding of the synthesis process ${ }^{7,40,41}$. Here, we focused on how crystallite size varies with $\mathrm{NaOAC} /$ $\mathrm{FeCl}_{3} \cdot 6 \mathrm{H}_{2} \mathrm{O}$ ratio and $\mathrm{H}_{2} \mathrm{O}$ content in terms of which crystallization pathway covers the entire reaction (see Supplementary Section 13). Increasing the content ratio of $\mathrm{FeCl}_{3} \cdot 6 \mathrm{H}_{2} \mathrm{O}$ (the $\mathrm{Fe}$ precursor) to that of $\mathrm{NaOAC}$ and $\mathrm{H}_{2} \mathrm{O}$ (the $\mathrm{OH}^{-}$sources) can lead to a reduction in crystallite size, implying that pathway 1 gradually accounts for the entire reaction. The reason could be the effect of excess $\mathrm{Fe}^{3+}$ cations, which could be reduced to $\mathrm{Fe}^{2+}$ by the subsequent reaction with ethylene glycol. As the $\mathrm{Fe}^{2+}$ concentration increases, it is adsorbed onto the surface of the iron (oxyhydr)oxide phases, and it transfers electrons to the bulk iron (oxyhydr)oxide, thus promoting nucleation of $\mathrm{Fe}_{3} \mathrm{O}_{4}{ }^{21,22,42}$. As shown in Fig. $5 \mathrm{c}$, when $\mathrm{H}_{2} \mathrm{O}$ is added in excess to the $\mathrm{NaOAC} /$ $\mathrm{FeCl}_{3} \cdot 6 \mathrm{H}_{2} \mathrm{O}$ ratio, the $\mathrm{Fe}_{3} \mathrm{O}_{4}$ phase is no longer formed, and the reaction is blocked at the intermediate phase. This is because excess $\mathrm{H}_{2} \mathrm{O}$ interferes with dehydration in the stepwise phase transformation of pathway $2^{43}$. 

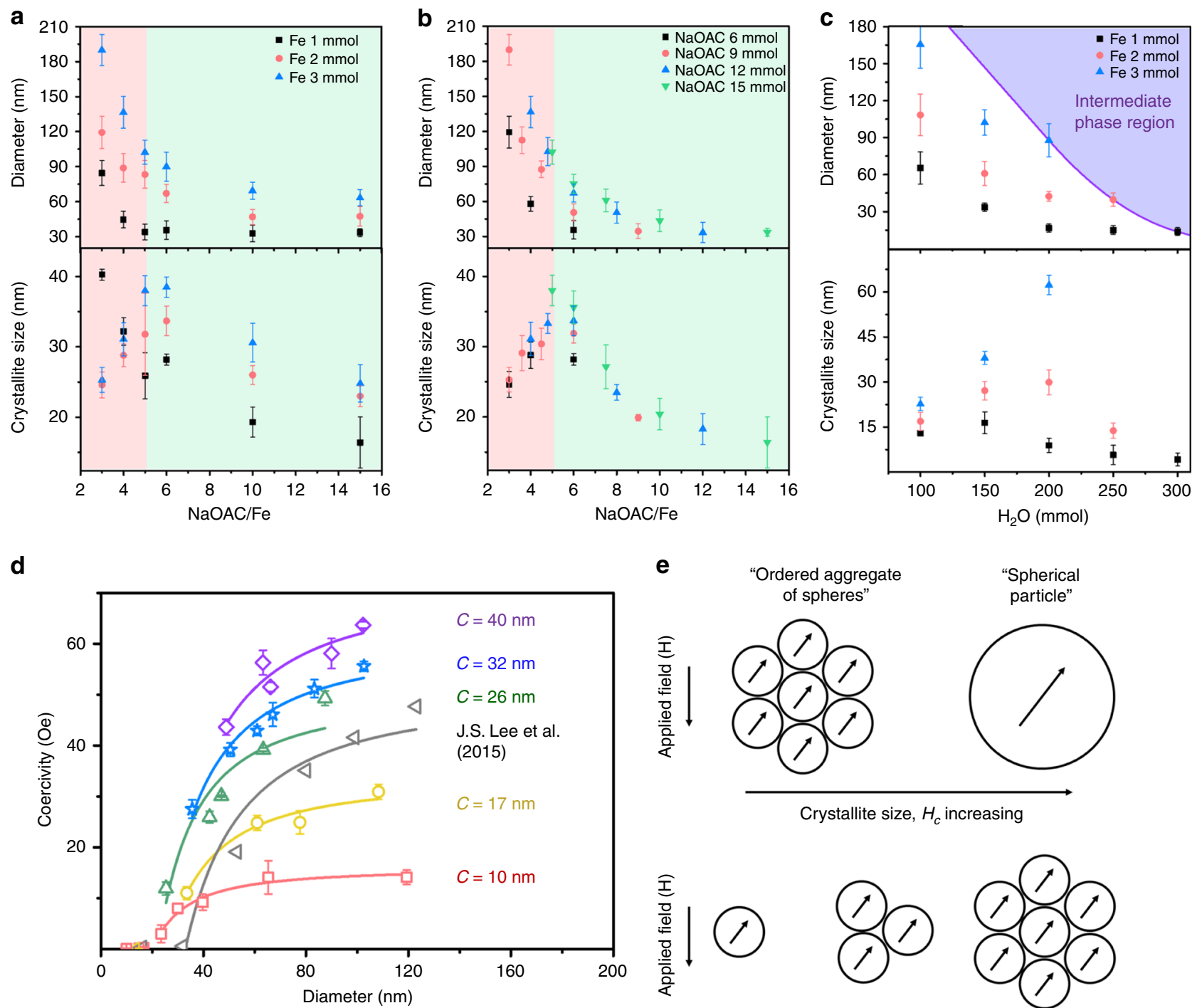

Ordered aggregate

"Spherical of spheres"

particle"
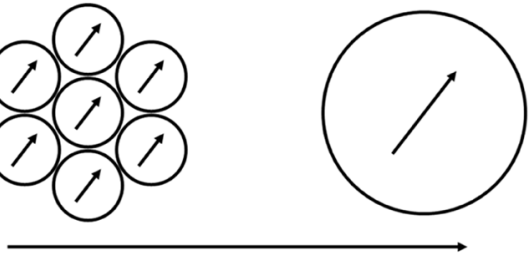

Crystallite size, $H_{c}$ increasing
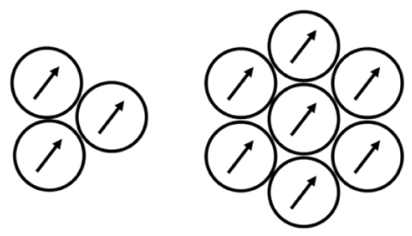

Number sphere $(n), H_{c}$ increasing

Fig. 5 Crystallite size effect on $\boldsymbol{H}_{\mathbf{c}}$ fitting as a function of the diameter of the mesocrystal. a Effect of $\mathrm{NaOAC}, \mathbf{b}$ Fe precursor, and $\mathbf{c} \mathrm{H}_{2} \mathrm{O}$ contents on the diameter and crystallite size of $\mathrm{Fe}_{3} \mathrm{O}_{4}$ mesocrystals. Red and green regions denote the regions where the crystallization pathways 1 and 2 , respectively, govern the entire reaction. The solid purple line serves as a guide to the eye. Error bars indicate standard deviations. $\mathbf{d} H_{\mathrm{c}}$ fitting depending on the diameter and crystallite size of the $\mathrm{Fe}_{3} \mathrm{O}_{4}$ mesocrystals. We expressed $H_{c}$ as a function of the mesocrystal diameter for five groups with different average crystallite sizes. Error bars indicate standard deviations. The smallest mesocrystal for each group is almost a single crystal with a diameter comparable to the crystallite size. The fitted curves are represented by solid lines. e Schematic illustration of $\mathrm{Fe}_{3} \mathrm{O}_{4}$ mesocrystal as an ordered aggregate of spheres.

A model for the magnetic coercivity behavior. Based on an understanding of the reaction, we can precisely control the diameter and crystallite size of $\mathrm{Fe}_{3} \mathrm{O}_{4}$ mesocrystals (Supplementary Figs. 9-12) and analyze the effect of crystallite size on $H_{c}$ (Fig. 5d). Figure $5 \mathrm{~d}$ presents the $\mathrm{H}_{\mathrm{c}}$ variation of $\mathrm{Fe}_{3} \mathrm{O}_{4}$ mesocrystals as a function of diameter below $D_{\mathrm{s}}$ for five groups representing different crystallite sizes; the crystallite size of each group of mesocrystals is kept constant. $D_{\mathrm{s}}$ is the critical size at which a particle changes from single magnetic domain to multiple domains and is $105 \mathrm{~nm}$ for $\mathrm{Fe}_{3} \mathrm{O}_{4}{ }^{7}$. All the groups fit the empirical equation $H_{\mathrm{c}}=g+\frac{h}{D^{3 / 2}}\left(\right.$ when $\left.D<D_{\mathrm{s}}\right)$ well, where $a, g$, and $h$ are constants, and $D$ is the mesocrystal diameter ${ }^{2} . H_{c}$ shows a consistent relationship with $D^{-3 / 2}$ as it decreases in inverse proportion to the square root of the volume, like in Sharrock's time-dependent $H_{\mathrm{c}}$ expression ${ }^{44}$. The empirical constant $g$ increases with increasing crystallite size, while $h$ decreases
(Supplementary Table 1). The $H_{\mathrm{c}}$ curve of the group with larger crystallites increases more steeply. The fitted $H_{c}$ curve from our previous study is included for reference ${ }^{8}$, and it increases more rapidly than the $H_{c}$ curve in this study because the crystallite sizes of the samples used in the reference increased with increasing mesocrystal diameter. This implies that the $H_{c}$ curve fitting we obtained reflects the crystallite change accurately. Because the crystallites are magnetically coupled, in a manner reminiscent of mesocrystals, the $\mathrm{Fe}_{3} \mathrm{O}_{4}$ mesocrystals behave like a single particle. However, the $\mathrm{Fe}_{3} \mathrm{O}_{4}$ mesocrystals are simultaneously influenced by the individual size effect of the crystallite, which is a subunit of $\mathrm{Fe}_{3} \mathrm{O}_{4}$ mesocrystals ${ }^{1,3,9}$. According to Jacobs and Bean's chain-ofspheres model, the coercive force required for a magnetically coupled chain-of-spheres is lower than that of an ellipsoid with the axial ratio of the Stoner-Wohlfarth model ${ }^{3}$. The $\mathrm{Fe}_{3} \mathrm{O}_{4}$ mesocrystals are an aggregate of crystallites with the same 
crystallographic orientation and can be represented as ordered aggregate of spheres (Fig. 5e). The ordered aggregate of spheres needs a lower coercive force to reverse the magnetic moment than that for a spherical particle of the same volume. Furthermore, when an aggregate is composed of smaller spheres, $H_{\mathrm{c}}$ is reduced because the magnetically coupled interface increases. As the number of constituent spheres increases, $H_{c}$ gradually increases. This suggests that the chain-of-spheres model can also be adopted in spherical models that neglect shape anisotropy.

\section{Discussion}

We have discovered a new approach to chemically control the microstructure of $\mathrm{Fe}_{3} \mathrm{O}_{4}$ mesocrystals based on the crystallization pathways, which suggests that the polymorphism of iron (oxyhydr)oxide intermediates can affect the crystallization mechanism. We demonstrate that the growth mechanism of $\mathrm{Fe}_{3} \mathrm{O}_{4}$ mesocrystals from different iron (oxyhydr)oxide polymorphs leads to a variation in the microstructure of the mesocrystal characterized by the JMAK model. The former pathway, following oriented attachment, produces a small crystallite, while the latter, following the classical model by stepwise transformation, produces a large crystallite. These two parallel crystallization pathways operate competitively, and we were able to selectively control the ratio of the pathways that govern the entire reaction depending on the $\mathrm{NaOAC} / \mathrm{FeCl}_{3} \cdot 6 \mathrm{H}_{2} \mathrm{O}$ ratio and $\mathrm{H}_{2} \mathrm{O}$ content. We hereby propose the $H_{c}$ model for $\mathrm{Fe}_{3} \mathrm{O}_{4}$ mesocrystals $100 \mathrm{~nm}$ or less in size, which facilitates fundamental magnetism in fine particles. To the best of our knowledge, this is the first report of $H_{\mathrm{c}}$ variation in $\mathrm{Fe}_{3} \mathrm{O}_{4}$ mesocrystals synthesized using the same method as a function of both diameter and crystallite size. The $\mathrm{Fe}_{3} \mathrm{O}_{4}$ mesocrystals synthesized via chemical routes, with diameters ranging from a few nanometers to a hundred nanometers and exhibiting soft magnetism, are of emerging technological interests in electrical as well as biomedical applications. This study suggests a reliable design rule where coercivity modulation is desirable.

\section{Methods}

Synthesis of $\mathrm{Fe}_{\mathbf{3}} \mathbf{O}_{\mathbf{4}}$ mesocrystals. We use a modified polyol method that has been widely employed to synthesize metal/metal oxide mesocrystals with a controlled diameter in a wide range $\mathrm{e}^{7,35}$. This method is effective for investigating the prenucleation attachment model of $\mathrm{Fe}_{3} \mathrm{O}_{4}$ mesocrystal formation and explaining changes in the geometric and microstructural sizes. The experimental procedure is as follows: we use iron chloride hexahydrate $\left(\mathrm{FeCl}_{3} \cdot 6 \mathrm{H}_{2} \mathrm{O}\right)$, sodium acetate (NaOAC), and ethylene glycol (which are commonly used in the modified polyol method) as the Fe precursor, hydroxyl ion supplier, and solvent, respectively. We do not use any other surfactant or modifier. In a typical synthesis of $\mathrm{Fe}_{3} \mathrm{O}_{4}$ mesocrystals, $\mathrm{FeCl}_{3} \cdot 6 \mathrm{H}_{2} \mathrm{O}, \mathrm{NaOAC}$, and distilled water are completely dissolved in $50 \mathrm{~mL}$ of ethylene glycol under vigorous mechanical stirring to form a yellow-brown turbid solution. $\mathrm{FeCl}_{3} \cdot 6 \mathrm{H}_{2} \mathrm{O}(>97 \%$, Sigma-Aldrich, Korea), $\mathrm{NaOAC}$ ( $>98.5 \%$, Sigma-Aldrich, Korea), and ethylene glycol ( $>99.5 \%$, Samchun Chemicals, Korea) are used as received. We add distilled water (Millipore Direct-Q UV 3) to the weighed $\mathrm{FeCl}_{3} \cdot 6 \mathrm{H}_{2} \mathrm{O}$ powder to obtain the appropriate concentration. Next, the desired volume of $\mathrm{FeCl}_{3} \cdot 6 \mathrm{H}_{2} \mathrm{O}$ aqueous solution is injected rapidly into the ethylene glycol solution containing NaOAC. Here, the ratios of $\mathrm{FeCl}_{3} \cdot 6 \mathrm{H}_{2} \mathrm{O}, \mathrm{NaOAC}$, and distilled water should be carefully controlled because they significantly influence the diameter and crystallite size of the final $\mathrm{Fe}_{3} \mathrm{O}_{4}$ mesocrystals. The solution is then refluxed for $8 \mathrm{~h}$, during which period it turns reddish-brown and then slowly becomes black. The temperature is set to $200^{\circ} \mathrm{C}$, but the size of the mesocrystals can be controlled by adjusting the duration of the reaction at temperatures between 70 and $90^{\circ} \mathrm{C}$. After cooling to room temperature, the black sediment is washed upwards of five times using ethanol and distilled water to eliminate any organic and inorganic by-products. To monitor the formation process of the mesocrystals, the experiments are stopped after refluxing for the desired time, and the samples stored at room temperature. For $\mathrm{S} 1$, we synthesize the $\mathrm{Fe}_{3} \mathrm{O}_{4}$ mesocrystals following the preceding procedure and using $2 \mathrm{mmol}$ of $\mathrm{FeCl}_{3} \cdot 6 \mathrm{H}_{2} \mathrm{O}$, $15 \mathrm{mmol}$ of $\mathrm{NaOAC}, 150 \mathrm{mmol}$ of $\mathrm{H}_{2} \mathrm{O}$, and $50 \mathrm{~mL}$ of ethylene glycol. Refluxing is performed at $200^{\circ} \mathrm{C}$, and we stop the experiment at $30 \mathrm{~min}$ or $1 \mathrm{~h}$ intervals. The reaction mixture is cooled to room temperature and stored at $4{ }^{\circ} \mathrm{C}$ in a refrigerator. $\mathrm{S} 2$ is prepared in the same way as $\mathrm{S} 1$, but different amounts of the precursors are used, as follows: $1 \mathrm{mmol}$ of $\mathrm{FeCl}_{3} \cdot 6 \mathrm{H}_{2} \mathrm{O}, 3 \mathrm{mmol}$ of $\mathrm{NaOAC}, 200 \mathrm{mmol}$ of $\mathrm{H}_{2} \mathrm{O}$, and $50 \mathrm{~mL}$ of ethylene glycol. We adjust the concentration of each precursor individually to analyze the changes in the diameter and crystallite size of the $\mathrm{Fe}_{3} \mathrm{O}_{4}$ mesocrystals according to the $\mathrm{OH}^{-} / \mathrm{Fe}^{3+}$ ratio. To analyze the effects of $\mathrm{NaOAC}, 2$, $3,4,5,6,10$, and $15 \mathrm{mmol}$ of $\mathrm{NaOAC} / \mathrm{FeCl}_{3} \cdot 6 \mathrm{H}_{2} \mathrm{O}$ is used, and the amount of $\mathrm{FeCl}_{3} \cdot 6 \mathrm{H}_{2} \mathrm{O}$ is constant at 1,2 , and $3 \mathrm{mmol}$. To analyze the effects of $\mathrm{Fe}^{3+}, 1,1.5,2$, 2.5 , and $3 \mathrm{mmol}$ of $\mathrm{FeCl}_{3} \cdot 6 \mathrm{H}_{2} \mathrm{O}$ is used, with $6,9,12$, or $15 \mathrm{mmol}$ of $\mathrm{NaOAC}$. Furthermore, the amount of distilled water is varied from 100 to $300 \mathrm{mmol}$ while the $\mathrm{NaOAC} / \mathrm{FeCl}_{3} \cdot 6 \mathrm{H}_{2} \mathrm{O}$ ratio is maintained at $15,7.5$, or 5 . We successfully determined the trends in size change of the mesocrystals and crystallites.

Characterization of $\mathrm{Fe}_{3} \mathrm{O}_{4}$ mesocrystals. The morphology and microstructural evolution of the crystallization pathways of the $\mathrm{Fe}_{3} \mathrm{O}_{4}$ mesocrystals are determined using analytical TEM (FEI, Talos F200X) at $200 \mathrm{kV}$. To observe the formation process of $\mathrm{Fe}_{3} \mathrm{O}_{4}$ mesocrystals in $\mathrm{S} 1$ and $\mathrm{S} 2$ at different times while preserving the samples, a crude solution is used for sampling on a TEM grid without washing or dilution. We drop $6 \mu \mathrm{L}$ of the solution onto a carbon-coated copper grid. Next, the intermediate and $\mathrm{Fe}_{3} \mathrm{O}_{4}$ mesocrystals are adsorbed on the grid for approximately 3 $h$ in a vacuum desiccator, and the remaining solution is removed via filter paper. The samples for the TEM experiments are prepared by diluting washed samples using absolute ethanol and then placing a drop of the sample solution on a carboncoated copper grid. The sizes of $n>500 \mathrm{Fe}_{3} \mathrm{O}_{4}$ mesocrystals and $n>50$ primary $\mathrm{Fe}_{3} \mathrm{O}_{4}$ crystallites are measured from the TEM images. The mean value is obtained by fitting the counts using Gaussian distributions. The crystal structure and crystallite size of the emerging phases are determined using powder XRD (PANalytical, X'Pert ProMPD) with a Cu Ka radiation source $(\lambda=1.5406 \AA)$ at the Korea Basic Science Institute, Seoul Western Center. Measurements are performed in $\theta-2 \theta$ geometry from 20 to $80^{\circ}$ using a $45 \mathrm{kV}$ and $40 \mathrm{~mA}$ tube. The average crystallite size is calculated using the Williamson-Hall plot, considering the deformation factors of the samples. The crystallite sizes are determined using the Williamson-Hall plot after the profiles of the samples are fitted with a pseudo-Voigt function, and instrumental broadening is corrected. The XRD peak broadening induced by microstrain $\left(\varepsilon \approx \frac{\beta \mathrm{s}}{\tan \theta}\right)$ is considered in estimating the crystallite size. The size and strain broadening at different $\theta$ positions are analyzed using the Williamson-Hall plot and the uniform deformation model, assuming that the microstrain is uniform in all crystallographic directions and the crystallite size and strain contribute independently to line broadening. The strain and crystallite size are calculated from the slope and $y$-intercept of a linear fitting. Samples S1 and S2 have crystallite sizes of 23 and $43 \mathrm{~nm}$, respectively (Supplementary Fig. 2). Raman spectra of $\mathrm{Fe}_{3} \mathrm{O}_{4}$ mesocrystal and ferric (oxyhydr)oxide intermediates were obtained with a confocal-Raman spectrometer (Renishaw, InVia Raman microscope) equipped with a equipped with a Nd-YAG laser operating at $532 \mathrm{~nm}$ and a 1200 lines $/ \mathrm{mm}$ grating. Vacuum dried samples were mounted onto a glass. The samples were measured at $1 \mathrm{~s}$ detector exposure time with 100 spectra accumulations using a low laser power of $1 \%$ to avoid any damages in the sample. The magnetic properties of the powdered samples are analyzed by measuring the magnetization curves $M(H)$ using a vibrating sample magnetometer (Microsense, EV9). We measure $M(H)$ at $300 \mathrm{~K}$ using an applied field of up to $20 \mathrm{kOe}$.

JMAK model of crystallization of $\mathrm{Fe}_{3} \mathrm{O}_{\mathbf{4}}$ mesocrystals. We tried to demonstrate two observed crystallization pathways using JMAK kinetics. Because neither S1 nor S2 contains any phase other than $\mathrm{Fe}_{3} \mathrm{O}_{4}$ after the reaction is complete, we regard $f$ as the volume fraction of $\mathrm{Fe}_{3} \mathrm{O}_{4}$ mesocrystals transformed from the appropriate intermediate. Thus, the JMAK equation yields the following: $f=1-\exp \left[-(k t)^{n}\right]$, $\frac{V_{t}}{V_{\mathrm{f}}}=1-\exp \left[-(k t)^{n}\right]$, where $f$ is the volume fraction of the transformed material, $t$ is the transformation time, $k$ is a constant, and $n$ is the Avrami exponent. $V_{\mathrm{t}}$ is the volume of $\mathrm{Fe}_{3} \mathrm{O}_{4}$ mesocrystals grown at each transformation time, and $V_{\mathrm{f}}$ is the final volume of $\mathrm{Fe}_{3} \mathrm{O}_{4}$ mesocrystals from each intermediate. The Avrami exponent can be written as follows: $n=a+(b \times c)$, where $a$ is the time-dependent nucleation rate $(a>0), b$ is the dimensionality of the grown phase $(0<b<3)$, and $c$ is the growth rate $(c=0.5$ or 1$)$. The value of $a$ indicates the nucleation rate as follows: $a=0$ (no nucleation or preexisting nuclei), $0<a<1$ (decreasing nucleation), $a=1$ (constant nucleation), $a>1$ (increasing nucleation). The value of $c$ indicates the relationship between time and size based on the growth mode, where $c=0.5$ for diffusion-controlled growth and $c=1$ for interface-controlled growth. We apply the JMAK model to each pathway separately. This is possible because the $\mathrm{Fe}_{3} \mathrm{O}_{4}$ growth from lepidocrocite can be distinguished from that from goethite based on time. When $\mathrm{Fe}_{3} \mathrm{O}_{4}$ crystals are derived from lepidocrocite or goethite, the growth kinetics operate differently. For S1, the formation process can be divided into two pathways: an early-stage process (up to $3.5 \mathrm{~h}$ ), and a late-stage process (from 3.5 to $8 \mathrm{~h}$ ). As shown in the JMAK model timeline of $\mathrm{S} 1$, the $\mathrm{Fe}_{3} \mathrm{O}_{4}$ core grows via pathway 1, and then the $\mathrm{Fe}_{3} \mathrm{O}_{4}$ shell grows via pathway 2 (Supplementary Fig. 8).

For pathway 1 of $\mathrm{S} 1$ (from $\mathrm{Lp}$ to $\mathrm{Fe}_{3} \mathrm{O}_{4}, t_{\text {reflux }}=0-2.5 \mathrm{~h}, t_{\text {trans, pathwayl }}=0-2.5 \mathrm{~h}$ ):

$$
\frac{\frac{4}{3} \pi r_{t_{\text {trans pathway }} 3^{3}}}{\frac{4}{3} \pi r_{1}^{3}}=1-\exp \left[-\left(k t_{\text {trans, pathwayl }}\right)^{n}\right]
$$

For pathway 2 of $\mathrm{S} 1$ (from $\mathrm{Gt}$ to $\mathrm{Fe}_{3} \mathrm{O}_{4}, t_{\text {reflux }}=3.5-8 \mathrm{~h}, t_{\text {trans, pathway } 2}=0-4.5 \mathrm{~h}$ ):

$$
\frac{\frac{4}{3} \pi r_{t_{\text {trans }} \text { pathway }}-\frac{4}{3} \pi r_{1}^{3}}{\frac{4}{3} \pi r_{2}^{3}-\frac{4}{3} \pi r_{1}^{3}}=1-\exp \left[-\left(k t_{\text {trans, pathway } 2}\right)^{n}\right]
$$


For S2, because the $\mathrm{Fe}_{3} \mathrm{O}_{4}$ mesocrystals are formed primarily from goethite, we considered the refluxing time of $3 \mathrm{~h}$ at which $\mathrm{Fe}_{3} \mathrm{O}_{4}$ crystals start to form, as $t_{\text {trans }}=0$. For pathway 2 of S2 (from Gt to $\mathrm{Fe}_{3} \mathrm{O}_{4}, t_{\text {reflux }}=3-8 \mathrm{~h}, t_{\text {trans, pathway } 2}=$ $0-5 \mathrm{~h})$ :

$$
\frac{\frac{4}{3} \pi r_{t_{\text {trans, pathway }} \text { p }^{3}}-\frac{4}{3} \pi r_{1}^{3}}{\frac{4}{3} \pi r_{2}^{3}-\frac{4}{3} \pi r_{1}^{3}}=1-\exp \left[-\left(k t_{\text {trans, pathway2 }}\right)^{n}\right]
$$

\section{Data availability}

The data that support the findings of this study are available from the corresponding author upon reasonable request.

Received: 6 July 2019; Accepted: 16 December 2019;

Published online: 15 January 2020

\section{References}

1. Cullity, B. D. \& Graham, C. D. Introduction to Magnetic Materials 2nd ed Ch. 11 (Wiley, Hoboken, New Jersey, 2011).

2. Kneller, E. F. \& Luborsky, F. E. Particle size dependence of coercivity and remanence of single-domain particles. J. Appl. Phys. 34, 656-658 (1963).

3. Jacobs, I. S. \& Bean, C. P. An approach to elongated fine-particle magnet. Phys. Rev. 100, 1060-1067 (1955).

4. Silveyra, J. M., Ferrara, E., Huber, D. L. \& Monson, T. C. Soft magnetic materials for a sustainable and electrified world. Science 362, eaao0195 (2018).

5. Shin, T. H., Choi, Y., Kim, S. \& Cheon, J. Recent advances in magnetic nanoparticle-based multi-modal imaging. Chem. Soc. Rev. 44, 4501-4516 (2015).

6. Bobo, D. et al. Nanoparticle-based medicines: a review of FDA-approved materials and clinical trials to date. Pharm. Res. 33, 2373-2387 (2016).

7. Deng, H. et al. Monodisperse magnetic single-crystal ferrite microspheres. Angew. Chem. Int. Ed. 44, 2782-2785 (2005).

8. Lee, J. S. et al. Magnetic multi-granule nanoclusters: a model system that exhibits universal size effect of magnetic coercivity. Sci. Rep. 5, 12135 (2015).

9. Reichel, V. et al. Single crystalline superstructured stable single domain magnetite nanoparticles. Sci. Rep. 7, 45484 (2017).

10. Chung, S. Y., Kim, T. M., Kim, J. G. \& Kim, Y. J. Multiphase transformation and Ostwald's rule of stages during crystallization of a metal phosphate. Nat. Phys. 5, 68-73 (2009).

11. Peng, Y. et al. Two-step nucleation mechanism in solid-solid phase transitions. Nat. Mater. 14, 101-108 (2015).

12. Zahn, D. Thermodynamics and kinetics of prenucleation clusters, classical and non-classical nucleation. ChemPhysChem 16, 2069-2075 (2015).

13. Ostwald, W. Studien uber die bildung und umwandlung fester korper. Z. Phys. Chem. 22, 289-330 (1897).

14. Lee, J., Yang, J., Kwon, S. G. \& Hyeon, T. Nonclassical nucleation and growth of inorganic nanoparticles. Nat. Rev. Mater. 1, 16034 (2016).

15. Yoreo, J. J. D. et al. Crystallization by particle attachment in synthetic, biogenic, and geologic environments. Science 349, aaa6760 (2015).

16. Colfen, H. \& Antonietti, M. Mesocrystals and Nonclassical Crystallization. Ch. 4 (Wiley, Chichester, 2008).

17. Gebauer, D. et al. Pre-nucleation clusters as solute precursors in crystallization. Chem. Soc. Rev. 43, 2348-2371 (2014).

18. Gebuer, D., Volkel, A. \& Colfen, H. Stable prenucleation calcium carbonate clusters. Science 322, 1819-1822 (2008).

19. Dey, A. et al. The role of prenucleation clusters in surface-induced calcium phosphate crystallization. Nat. Mater. 9, 1010-1014 (2010).

20. Stawski, T. M. et al. Formation of calcium sulfate through the aggregation of sub-3 nanometre primary species. Nat. Commun. 7, 11177 (2016).

21. Hansel, C. M., Benner, S. G. \& Fendorf, S. Competing Fe(II)-induced mineralization pathways of ferrihydrite. Environ. Sci. Technol. 39, 7147 (2005).

22. Vali, H. et al. Formation of tabular single-domain magnetite induced by Geobacter metallireducens GS-15. Proc. Natl Acad. Sci. USA 101, 16121-16126 (2004).

23. Navrotsky, A., Mazeina, L. \& Majzlan, J. Size-driven structural and thermodynamic complexity in iron oxides. Science 319, 1635-1638 (2008).

24. Baumgartner, J. \& Faivre, D. Iron solubility, colloids and their impact on iron (oxyhydr)oxide formation from solution. Earth Sci. Rev. 150, 520-530 (2015).

25. Stefansson, A. Iron(III) hydrolysis and solubility at $25^{\circ} \mathrm{C}$. Environ. Sci. Technol. 41, 6117 (2007)
26. Bernal, J. D., Dasgupta, D. R. \& Mackay, A. L. Oriented transformations in iron oxide and hydroxides. Nature 180, 645-647 (1957).

27. Li, D. et al. Direction-specific interactions control crystal growth by oriented attachment. Science 336, 1014-1018 (2012).

28. Baumgartner, J. et al. Nucleation and growth of magnetite from solution. Nat. Mater. 12, 310-314 (2013).

29. Scheck, J. et al. The molecular mechanism of iron(III) oxide nucleation. J. Phys, Chem. Lett. 7, 3123-3130 (2016)

30. Sun, S., Gebauer, D. \& Colfen, H. Alignment of amorphous iron oxide clusters: a non-classical mechanism for magnetite formation. Angew. Chem. Int. Ed. 56, 4042-4046 (2017)

31. Sturm, E. V. \& Colfen, H. Mesocrystals: structural and morphogenetic aspects. Chem. Soc. Rev. 45, 5821-5833 (2016).

32. Hanesch, M. Raman spectroscopy of iron oxides and (oxy)hydroxides at low laser power and possible applications in environmental magnetic studies. Geophys. J. Int. 177, 941-948 (2009).

33. Avrami, M. Kinetics of phase change. II Transformation-time relations for random distribution of nuclei. J. Chem. Phys. 8, 212-224 (1940).

34. Jeon, K. J. et al. Air-stable magnesium nanocomposites provide rapid and high-capacity hydrogen storage without using heavy-metal catalysts. Nat. Mater. 10, 286-290 (2011).

35. Xiang, K. et al. Mesoscopic phase transition kinetics in secondary particles of electrode-active materials in lithium-ion batteries. Chem. Mater. 30, 4216-4225 (2018)

36. Sun, W. \& Ceder, G. Induction time of a polymorphic transformation. CrystEngComm 19, 4576-4585 (2017).

37. Chen, B. R. et al. Understanding crystallization pathways leading to manganese oxide polymorph formation. Nat. Commun. 9, 2553 (2018).

38. Navrotsky, A. Energetic clues to pathways to biomineralization: precursors, clusters, and nanoparticles. Proc. Natl Acad. Sci. USA 101, 12096-12101 (2004).

39. Schwertmann, U. Solubility and dissolution of iron oxides. Plant Soil 130, $1-25$ (1991).

40. Peng, B., Zhang, X., Aarts, D. G. A. L. \& Dullens, R. P. A. Superparamagnetic nickel colloidal nanocrystal clusters with antibacterial activity and bacteria binding ability. Nat. Nanotechnol. 13, 478-482 (2018).

41. Lu, Z. \& Yin, Y. Colloidal nanoparticle clusters: functional materials by design. Chem. Soc. Rev. 41, 6874-6887 (2012).

42. Ahn, T. Formation pathways of magnetite nanoparticles by coprecipitation method. J. Phys. Chem. C 116, 6069-6076 (2012)

43. Cha, J. et al. Solid-state phase transformation mechanism for formation of magnetic multi-granule nanoclusters. RSC Adv. 3, 3631-3637 (2013).

44. Sharrock, M. P. Time-dependent magnetic phenomena and particle-size effects in recording media. IEEE Trans. Magn. 26, 193-197 (1990).

\section{Acknowledgements}

This research was supported through the National Research Foundation of Korea funded by the Ministry of Science and ICT (2014M3A7B4052192; 2019R1A2C3006587) and Ministry of Education (2019R1I1A1A01062020)

\section{Author contributions}

B.C.P. and Y.K.K. conceived and designed the experiments. J.C. and J.Y.N. performed the XRD experiments and analyzed the phase transformation. B.C.P., M.S.K., M.J.K. and L.P. optimized the synthesis conditions for the $\mathrm{Fe}_{3} \mathrm{O}_{4}$ mesocrystals. B.C.P., J.C. and M.S.K. analyzed the characteristics and crystallization pathway of the $\mathrm{Fe}_{3} \mathrm{O}_{4}$ mesocrystals. Y.K.K. supervised the entire project. B.C.P. and J.C. wrote the manuscript after discussions with all the authors.

\section{Competing interests}

The authors declare no competing interests.

\section{Additional information}

Supplementary information is available for this paper at https://doi.org/10.1038/s41467 019-14168-0.

Correspondence and requests for materials should be addressed to Y.K.K.

Peer review information Nature Communications thanks Damien Faivre and the other anonymous reviewers for their contribution to the peer review of this work.

Reprints and permission information is available at http://www.nature.com/reprints

Publisher's note Springer Nature remains neutral with regard to jurisdictional claims in published maps and institutional affiliations. 
(c) (i) Open Access This article is licensed under a Creative Commons Attribution 4.0 International License, which permits use, sharing, adaptation, distribution and reproduction in any medium or format, as long as you give appropriate credit to the original author(s) and the source, provide a link to the Creative Commons license, and indicate if changes were made. The images or other third party material in this article are included in the article's Creative Commons license, unless indicated otherwise in a credit line to the material. If material is not included in the article's Creative Commons license and your intended use is not permitted by statutory regulation or exceeds the permitted use, you will need to obtain permission directly from the copyright holder. To view a copy of this license, visit http://creativecommons.org/ licenses/by/4.0/.

(C) The Author(s) 2020 